\title{
Micafungin may be safely administered as outpatient parenteral antimicrobial therapy for chronic pulmonary aspergillosis
}

DOI:

10.1111/myc. 12857

\section{Document Version}

Accepted author manuscript

Link to publication record in Manchester Research Explorer

Citation for published version (APA):

Otu, A. A., Bongomin, F., Bazaz, R., Harris, C., Denning, D. W., \& Kosmidis, C. (2018). Micafungin may be safely administered as outpatient parenteral antimicrobial therapy for chronic pulmonary aspergillosis. MYCOSES. https://doi.org/10.1111/myc.12857

\section{Published in:}

MYCOSES

\section{Citing this paper}

Please note that where the full-text provided on Manchester Research Explorer is the Author Accepted Manuscript or Proof version this may differ from the final Published version. If citing, it is advised that you check and use the publisher's definitive version.

\section{General rights}

Copyright and moral rights for the publications made accessible in the Research Explorer are retained by the authors and/or other copyright owners and it is a condition of accessing publications that users recognise and abide by the legal requirements associated with these rights.

\section{Takedown policy}

If you believe that this document breaches copyright please refer to the University of Manchester's Takedown Procedures [http://man.ac.uk/04Y6Bo] or contact uml.scholarlycommunications@manchester.ac.uk providing relevant details, so we can investigate your claim.

\section{OPEN ACCESS}


DR AKANINYENE OTU (Orcid ID : 0000-0002-6009-2707)

DR FELIX BONGOMIN (Orcid ID : 0000-0003-4515-8517)

Article type : Original Article

Micafungin may be safely administered as outpatient parenteral antimicrobial therapy for chronic pulmonary aspergillosis

Akaninyene A. Otu ${ }^{1,2^{*}}$, Felix Bongomin ${ }^{2, \#}$, Rohit Bazaz², Chris Harris²,

David W. Denning ${ }^{2,3,4}$, Chris Kosmidis $2,3,4$

1. Department of Internal Medicine, University of Calabar, Calabar, Cross River State, Nigeria.

2. The National Aspergillosis Centre, ECMM Centre of Excellence in Clinical and Laboratory Mycology and Clinical Studies, Wythenshawe Hospital, Manchester University NHS Foundation Trust, Southmoor Road, Manchester M23 9LT, United Kingdom

3. Faculty of Biology, Medicine and Health, The University of Manchester, Oxford Rd, Manchester M13 9PL, United Kingdom

4. Manchester Academic Health Science Centre, 2nd Floor Education and Research Centre, Wythenshawe Hospital, Manchester University NHS Foundation Trust, Southmoor Road, Manchester M23 9LT, United Kingdom

${ }^{\#}$ Current address: Department of Medical Microbiology \& Immunology, Faculty of Medicine, Gulu University, Gulu, Uganda.

This article has been accepted for publication and undergone full peer review but has not been through the copyediting, typesetting, pagination and proofreading process, which may lead to differences between this version and the Version of Record. Please cite this article as doi: $10.1111 /$ myc. 12857

This article is protected by copyright. All rights reserved. 


\section{${ }^{*}$ Corresponding Author:}

Akaninyene Otu

Senior Clinical Fellow Infectious Diseases

The National Aspergillosis Centre, 2nd Floor Education and Research Centre, Wythenshawe Hospital, Manchester University NHS Foundation Trust, Southmoor Road, Manchester M23 9LT, United Kingdom

Tel: +447561045554; Fax: 01612915866

e-mail: akanotu@yahoo.com

\section{Short running title:}

Micafungin therapy for CPA via OPAT

\section{Abstract.}

\section{Background}

Intravenous micafungin has been reported as a treatment alternative in patients with chronic pulmonary aspergillosis (CPA) where long-term oral triazole therapy is unfeasible.

\section{Objectives}

We evaluated the safety and efficacy of micafungin administered via the outpatient parenteral antimicrobial therapy (OPAT) service for the treatment of CPA

\section{Methods}

We included all CPA patients who received micafungin via OPAT between April 2016 and March 2018. Data on adverse events and line-related complications, and Quality of Life $(\mathrm{QoL})$ scores at the start of micafungin course and 3 months later were extracted.Improvements in QOL were defined as an improvement of $\geq 4$ points in at least one modality (symptom, impact, activity, total) in the St George's QOL score. A stable QOL score was defined as a change in score of less than 4 points in either direction whilst deterioration was defined as an increase of $\geq 4$ points. 


\section{Results}

There were 20 OPAT episodes involving 18 patients with a median duration of micafungin therapy of 21 (range: 4-248) days. Improvement or stability in the symptoms, activity, impact and total score was seen in $14(78 \%), 12(67 \%), 9(50 \%)$ and $9(50 \%)$ of the patients respectively. However, half of the patients reported deterioration in the impact domain and total scores. By self-assessment, patients who categorized themselves as "poor" was comparable at the start of OPAT and at 3 months ( $43 \%$ vs. $50 \%$, McNemar's p=0.7). Adverse events attributable to micafungin were recorded in 3 (14.3\%) episodes.

\section{Conclusions}

Micafungin may be safely administered via an OPAT service. Micafungin therapy was associated with an improvement or stability in QoL scores in at least $50 \%$ of the patients across the 4 domains.

\section{Introduction}

Chronic pulmonary aspergillosis (CPA) is a slowly progressive, destructive infection of the lungs, with radiological features characterized by cavity formation or enlargement of preexistent cavities with or without intra-cavitary aspergilloma, parenchymal fibrosis or pleural thickening. ${ }^{1,2}$ CPA is typically treated with long-term ( $\geq 6$ months) oral triazole antifungal therapy. Other antifungal agents such as the echinocandins may also be used in the setting of triazole intolerance, clinical failure of triazole therapy, laboratory confirmed triazole resistance or rapidly progressive disease ${ }^{3}$. The clinical response rate of micafungin for treatment of CPA has been reported to be as high as $78 \%{ }^{4-6}$

Outpatient parenteral antimicrobial therapy (OPAT) is used to deliver intravenous (IV) antimicrobials to patients with serious infections in an outpatient setting or in their own home. ${ }^{7,8}$ The OPAT service at the Wythenshawe Hospital site of Manchester University NHS 
Foundation Trust was established in 2015 and is run by a multidisciplinary team based in the Infectious Diseases Department, which also incorporates the National Aspergillosis Centre (NAC). The OPAT service has facilitated the discharge from hospital of patients requiring IV micafungin for treatment of their CPA. Here, we reviewed OPAT episodes during which CPA patients received micafungin.

\section{Materials and Methods}

All CPA patients who completed a course of micafungin through OPAT between April 2016 and March 2018 were included in the study. The diagnosis of CPA was made using a combination of characteristics: a consistent appearance on thoracic imaging, direct evidence of Aspergillus infection or an immunological response to Aspergillus spp. and exclusion of some alternative diagnoses ${ }^{7}$. All patients initially received micafungin as an inpatient before being discharged via OPAT. All patients received daily doses of IV micafungin (7 days a week). Some OPAT administered doses were initially given via peripheral cannulae but most doses were given via peripherally inserted central catheter (PICC) lines.

All data were collected retrospectively from case notes and the NAC database of CPA patients. Demographic, clinical and laboratory data were recorded. Where available, St George's Respiratory Questionnaire (SGRQ) Quality of Life (QoL) scores at the start of micafungin course and 3 months later were extracted to assess response to therapy. Improvements in QOL were defined as an improvement of $\geq 4$ points in at least one modality (symptom, impact, activity, total) in the St George's QOL score ${ }^{8}$. A stable QOL score was defined as a change in score of less than 4 points in either direction whilst deterioration was defined as an increase of $\geq 4$ points $^{9}$. The Symptoms component assesses for frequency and severity of disease; activity component assesses for activities of daily living that cause or are limited by breathlessness; Impact componentis the broadest component of the questionnaire that covers a vast range of disturbances of psychosocial function. The total score 
summarizes the impact of the disease on overall health status and is calculated using the formula ${ }^{10}$ :

Total score $=100 \times$ Summed weights from positive items in the questionnaire/Sum of weights for all items in the questionnaire

Scores for all components range from 0 to 100, with higher scores indicating more limitations. Best performances are achieved with a 3- or 12-month recall reported by the patient ${ }^{9}$

The Medical Research Council (MRC) dyspnoea score, patients' assessment of health status (self-assessments), and weight data were also recorded at the start of OPAT and 3 months later.

Categorical data were reported as total numbers and percentages. Normally distributed and non-normally distributed data were reported as mean or median values respectively. Continuous variables were compared using the paired t-test or Wilcoxon matched pairs signed rank test, as appropriate. McNemar's test was used to compare categorical data. Statistical significance was established at $\mathrm{p}<0.05$. GraphPad Prism v7.0d (GraphPad Software, La Jolla California USA) was used for data analysis.

\section{Results}

There were 20 OPAT episodes involving 18 patients (11males, 7 females), with 2 patients receiving 2 courses of micafungin during the study period. The indications for micafungin therapy were intolerance to azoles $(10 ; 48 \%)$, panazole resistance $(8 ; 38 \%)$ and rapid disease progression despite azole treatment $(3 ; 14 \%)$. The median age was 64 (range: $32-$ 84) years. The median duration of micafungin therapy via OPAT was 21 (range: 4-248) days (Table1). All patients received micafungin at a dose of 150mg OD. No therapeutic drug monitoring was carried out. One patient had IV ertapenem co-administered with micafungin while three patients received oral terbinafine $250 \mathrm{mg} B D$ as an adjuvant antifungal to micafungin. One patient received a total of 248 days of micafungin therapy. This patient had 
a background history of hyper lgE syndrome with interleukin 17 deficiency. He had panazole resistant Aspergillus fumigatus and experienced multiple episodes of haemoptysis requiring two bronchial artery embolisations (BAE).

QoL data was available for 18 patients; improvement or stability in the symptoms and activity domains was observed in over two-thirds of the patients after 3 months of micafungin therapy. However, half of the patients reported deterioration in the impact domain and total scores (Table 1). Improvement in the symptoms, activity, impact and total score was seen in $8(44 \%), 5(28 \%), 7(39 \%)$ and $6(33 \%)$ of the patients respectively (Table 1). There was no statistical difference between QoL change and duration of treatment $(p=0.8)$. By selfassessment, patients who categorized themselves as "poor" were comparable at the start of OPAT and at 3 months ( $43 \%$ vs. $50 \%$, McNemar's $p=0.7)$.

There was no significant difference observed in either weight (61.0 vs.62.8kgs; $p=0.5)$ or MRC dyspnoea scores ( $4 / 5$ vs. $4 / 5, p=0.8)$ at the start of treatment and 3 months after treatment (Table 1)

No line-related complications were recorded during micafungin therapy. Of the 20 OPAT episodes, adverse events, which could be attributed to micafungin, were recorded in $3(14 \%)$ of these. All the adverse events were classed as type A adverse drug reactions. None of the OPAT episodes were discontinued due to adverse drug reactions and all patients completed their course of micafungin as planned. One patient developed hypomagnesaemia $(0.4$ $\mathrm{mmol} / \mathrm{L}$ and another had hyponatremia $(123 \mathrm{mmol} / \mathrm{l})$. Both these patients were not on any other drugs that could explain the electrolyte derangements other than micafungin. One patient developed diarrhoea and confusion within days of starting micafungin but micafungin was continued. This patient's symptoms resolved spontaneously after one week of micafungin therapy. A total of 2 of $(10 \%)$ of the OPAT episodes were characterized by readmission of the patient into hospital. On both occasions, the indication for the admission 
was recurrent hemoptysis; one required two bronchial artery embolization procedures and was subsequently switched to liposomal amphotericin B.

\section{Discussion}

About $10 \%$ of CPA patients at the NAC have received at least 1 course of either intravenous micafungin or liposomal amphotericin B during the course of their disease treatment ${ }^{11}$. Our experience with the use of short-courses of liposomal amphotericin in CPA patients has previously been reported ${ }^{12}$. Here, we have described our experience of administering micafungin to CPA patients via OPAT. At 3 months post commencement of micafungin, there was no significant change in weight or dyspnoea, and only a third of the patients had a clinically significant improvement in their quality of life. The clinical response seen was much less that those seen in reports of previous randomized clinical trials (RCTs) of micafungin with or without amphotericin B or triazoles ${ }^{6,13}$. This could be because the median duration of micafungin therapy was shorter in our study and our patients received micafungin as monotherapy as opposed to combination with amphotericin B and triazoles. Although Kohno $^{12}$ and colleagues reported a higher rate of adverse reactions (15.8\%) among a cohort of Japanese patients, these were all mild with the most common being abnormal liver function. In a retrospective study, Izumakawa ${ }^{7}$ and colleagues reported a higher effectiveness (75\%) of micafungin monotherapy than we did and no notable side effects were documented.

Since its development in the 1970s, the use of OPAT has become widespread in both primary and secondary care across many countries. The aims of OPAT include the improving patient experience, and provision of care closer to home thereby improving patient experience while decreasing cost and length of hospital stay. Following assessment to determine medical and social suitability by a doctor or specialist nurse, plans are put in place to ensure the efficient daily delivery of the drug with provision made for review by a health professional at regular intervals.

This article is protected by copyright. All rights reserved. 
Micafungin is an echinocandin that acts through inhibition of $\beta-(1,3)$-d-glucan synthase, an enzyme that is necessary for the synthesis of essential $\beta-(1,3)$-d-glucan of the Aspergillus cell wall. It is an ideal choice for OPAT because of its once daily parenteral dosage. Micafungin has been used in a mixed population of patients with subacute invasive aspergillosis (chronic necrotising) and CPA, with reasonable success rates (efficacy) and acceptable safety. ${ }^{4}{ }^{10}$ Reported doses used in previous studies ranged from $12.5 \mathrm{mg}$ to $300 \mathrm{mg}$ OD with adverse events rates between $0 \%$ and $16 \%{ }^{4,5,14}$. This is comparable with our data; we observed just over $10 \%$ of the patients developing adverse events. Common reported adverse events associated with micafungin include abdominal pain; anaemia; diarrhoea; fever; headache; hypocalcaemia; hypokalaemia; hypomagnesaemia; leukopenia; phlebitis; rash and vomiting.

\section{Limitations}

We focused on the duration of micafungin administration of micafungin via OPAT and did not assess for inpatient use of micafungin among this cohort. It is possible that some patients received several doses of micafungin as inpatients prior to discharge on OPAT. Also, we were unable to assess for radiological response at the end of the course of micafungin therapy; clear treatment outcome definitions for micafungin use in the setting of CPA are yet to be clearly established. Our study design was retrospective and our findings were limited to what information was available from records. However, to the best of our knowledge, this is the first study to assess the safety and efficacy of IV micafungin administered via OPAT services for the treatment of CPA.

\section{Conclusions}

Despite the above limitations, the present study has shown that for the majority of CPA patients who received micafungin via OPAT, the course of therapy was well tolerated and no adverse events were recorded. Although this is a small sample size, our experience of using micafungin resulted in lower rates of clinical response than previously reported. However, we were able to demonstrate that micafungin can be safely administered via OPAT, and 
therefore may have a role to play facilitating the discharge of patients requiring micafungin for other fungal infections, including Candida infections.

\section{Acknowledgements}

We are grateful to Victoria Dodd of the OPAT team in Wythenshawe Hospital for providing us with insights into the working of the OPAT team.

\section{Conflict of interest}

Denning and family hold Founder shares in F2G Ltd., a University of Manchester spin-out antifungal discovery company. He acts or has recently acted as a consultant to Astellas, Sigma Tau, Basilea,Scynexis, Cidara, Biosergen, Quintiles, Pulmatrix, Pulmocide and Zambon. In the last 3 years, he has been paid for talks on behalf of Astellas, Dynamiker, Gilead, Merck and Pfizer. He is a longstanding member of the Infectious Disease Society of America Aspergillosis Guidelines group, the European Society for Clinical Microbiology and Infectious Diseases Aspergillosis Guidelines group and the British Society for Medical Mycology Standards of Care committee. All the other co-authors have no conflict of interest to declare.

This article is protected by copyright. All rights reserved. 


\section{References}

1. Denning DW, Riniotis K, Dobrashian R, Sambatakou H. Chronic Cavitary and Fibrosing Pulmonary and Pleural Aspergillosis: Case Series, Proposed Nomenclature Change, and Review. Clin Infect Dis 2003; 37: S265-80. Available at: https://academic.oup.com/cid/article-lookup/doi/10.1086/376526.

2. Tochigi N, Ishiwatari T, Okubo $\mathrm{Y}$, et al. Histological study of chronic pulmonary aspergillosis. Diagn Pathol 2015; 10: 153. Available at: http://www.diagnosticpathology.org/content/10/1/153.

3. Maghrabi F, Denning DW. The Management of Chronic Pulmonary Aspergillosis: The UK National Aspergillosis Centre Approach. Curr Fungal Infect Rep 2017. Available at: http://link.springer.com/10.1007/s12281-017-0304-7.

4. Kohno S, Izumikawa $\mathrm{K}$, Kakeya $\mathrm{H}$, et al. Clinical efficacy and safety of micafungin in Japanese patients with chronic pulmonary aspergillosis: a prospective observational study. Med Mycol 2011; 49: 688-93. Available at: http://www.ncbi.nlm.nih.gov/pubmed/21355713.

5. Fujita M, Tao Y, Kajiki A, et al. The clinical efficacy and safety of micafungin-itraconazole combination therapy in patients with pulmonary aspergilloma. $J$ Infect Chemother Off $J$ Japan Soc Chemother 2012; 18: 668-74.

6. Izumikawa K, Ohtsu Y, Kawabata M, et al. Clinical efficacy of micafungin for chronic pulmonary aspergillosis. Med Mycol 2007; 45: 273-8.

7. Denning DW, Cadranel J, Beigelman-Aubry C, et al. Chronic pulmonary aspergillosis: Rationale and clinical guidelines for diagnosis and management. Eur Respir J 2016; 47: 4568. Available at: http://www.ncbi.nlm.nih.gov/pubmed/26699723.

8. Al-Shair K, Atherton GTW, Kennedy D, Powell G, Denning DW, Caress A. Validity and reliability of the St. George's respiratory questionnaire in assessing health status in patients with chronic pulmonary aspergillosis. Chest 2013; 144: 623-31.

9. Jones PW. Interpreting thresholds for a clinically significant change in health status in asthma and COPD. Eur Respir J 2002; 19: 398-404.

10. Jones PW, Quirk FH, Baveystock CM, Littlejohns P. A self-complete measure of health status for chronic airflow limitation. The St. George's Respiratory Questionnaire. Am Rev Respir Dis 1992; 145: 1321-7. Available at:

http://www.atsjournals.org/doi/abs/10.1164/ajrccm/145.6.1321?url_ver=Z39.882003\&rfr_id=ori:rid:crossref.org\&rfr_dat=cr_pub\%3Dpubmed.

11. Bongomin F, Harris C, Hayes G, Kosmidis C, Denning DW. Twelve-month clinical 
outcomes of 206 patients with chronic pulmonary aspergillosis Chotirmall SH, ed. PLoS One 2018; 13: e0193732. Available at: http://dx.plos.org/10.1371/journal.pone.0193732.

12. Newton PJ, Harris C, Morris J, Denning DW. Impact of liposomal amphotericin B therapy on chronic pulmonary aspergillosis. J Infect 2016: 1-11. Available at: http://dx.doi.org/10.1016/j.jinf.2016.06.001.

13. Kohno S, Izumikawa K, Ogawa K, et al. Intravenous micafungin versus voriconazole for chronic pulmonary aspergillosis: A multicenter trial in Japan. J Infect 2010; 61: 410-8.

Available at: http://dx.doi.org/10.1016/j.jinf.2010.08.005.

14. Kohno S, Izumikawa K, Yoshida M, et al. A double-blind comparative study of the safety and efficacy of caspofungin versus micafungin in the treatment of candidiasis and aspergillosis. Eur J Clin Microbiol Infect Dis 2013; 32: 387-97.

This article is protected by copyright. All rights reserved. 
Table 1: Patients demographic and clinical characteristics

\begin{tabular}{|c|c|c|c|c|c|c|c|c|c|c|c|c|c|c|c|}
\hline Patient & Sex & Age & $\begin{array}{l}\text { Primary underlying } \\
\text { condition }\end{array}$ & $\begin{array}{l}\text { Duration } \\
\text { of OPAT }\end{array}$ & Self-assessment ${ }_{0}$ & $\begin{array}{l}\text { Self- } \\
\text { assessment }\end{array}$ & Weight $_{0}$ & Weight $_{3}$ & $\mathbf{M R C}_{0}$ & $\mathrm{MRC}_{3}$ & Symptoms & Impact & Activity & Total & Comments \\
\hline 1 & $\mathrm{M}$ & 32 & $\begin{array}{l}\text { Previous pneumothorax } \\
\text { +Hyper IgG syndrome }\end{array}$ & 248 & Fair & Good & 86.6 & 83.1 & 2 & 2 & Deteriorated & Deteriorated & Deteriorated & Deteriorated & BAE $\times 2$ \\
\hline 2 & $\mathrm{M}$ & 60 & Previous pneumothorax & 10 & Poor & Very poor & 84.0 & 85.2 & 4 & 5 & Stable & Deteriorated & Stable & Deteriorated & \\
\hline 3 & $\mathrm{M}$ & 69 & Previous pneumothorax & 91 & Fair & Good & 84.6 & 81.0 & 3 & 3 & Deteriorated & Improved & Improved & Stable & \\
\hline 4 & $\mathrm{M}$ & 69 & Mycobacterium xenopii & 11 & Poor & Poor & 71.0 & 72.4 & 4 & 4 & Deteriorated & Deteriorated & Deteriorated & Deteriorated & \\
\hline 5 & $\mathrm{~F}$ & 68 & Tuberculosis & 10 & Poor & Poor & 45.2 & 42.4 & 3 & 5 & Stable & Deteriorated & Stable & Deteriorated & \\
\hline 6 & M & 47 & COPD, Tuberculosis & 21 & Good & Fair & 56.6 & 58.2 & $\begin{array}{l}\text { Not } \\
\text { done }\end{array}$ & $\begin{array}{l}\text { Not } \\
\text { done }\end{array}$ & Improved & Deteriorated & Deteriorated & Deteriorated & Hypomagnesaemia \\
\hline 7 & $\mathrm{~F}$ & 66 & Tuberculosis & 28 & Poor & Good & 46.4 & 50.2 & 4 & 3 & Improved & Improved & Improved & Improved & \\
\hline 8 & $\mathrm{~F}$ & 35 & Asthma & 83 & Poor & Good & 58.0 & 55.4 & 4 & 1 & Improved & Improved & Improved & Improved & Recurrent hemoptysis \\
\hline 9 & $\mathrm{M}$ & 70 & $\begin{array}{l}\text { Mycobacterium avium } \\
\text { complex }\end{array}$ & 4 & Fair & Fair & 71.0 & 67.4 & 2 & 2 & Improved & Improved & Stable & Improved & \\
\hline 10 & $\mathrm{M}$ & 73 & Tuberculosis & 15 & Fair & Good & 58.6 & 52.8 & 3 & 2 & Improved & Improved & Stable & Improved & Hyponatremia \\
\hline 11 & $\mathrm{M}$ & 74 & COPD & 21 & Very poor & Poor & 62.0 & 63.6 & 5 & 4 & Improved & Improved & Improved & Improved & \\
\hline 12 & $\mathrm{M}$ & 59 & Resected SCLC & 21 & Fair & Poor & 62.6 & 62.6 & 4 & 4 & Stable & Deteriorated & Deteriorated & Deteriorated & \\
\hline 13 & $\mathrm{M}$ & 67 & Tuberculosis & 8 & Fair & Poor & 70.0 & 66.7 & 2 & 2 & Improved & Deteriorated & Deteriorated & Deteriorated & \\
\hline 14 & $\mathrm{~F}$ & 64 & Sarcoidosis & 28 & Very poor & Very poor & 44.0 & 45.0 & 4 & 5 & Stable & Stable & Improved & Stable & \\
\hline 15 & $\mathrm{~F}$ & 40 & Previous pneumothorax & 21 & Good & Fair & 48.8 & 49.6 & 2 & 2 & Stable & Deteriorated & Deteriorated & Deteriorated & \\
\hline 16 & $\mathrm{~F}$ & 36 & Sarcoidosis & 21 & Good & Fair & 60.0 & 63.0 & 4 & 4 & Deteriorated & Deteriorated & Stable & Deteriorated & \\
\hline 17 & $\mathrm{M}$ & 59 & $\begin{array}{l}\text { Previous pneumothorax, } \\
\text { COPD }\end{array}$ & 22 & Poor & Poor & 85.8 & 88.0 & 5 & 4 & Stable & Stable & Stable & Stable & Diarrhoea and confusion \\
\hline 18 & F & 75 & $\begin{array}{l}\text { Rheumatoid arthritis, } \\
\text { COPD }\end{array}$ & 15 & Poor & Fair & 56.5 & 56.0 & 5 & 5 & Improved & Improved & Stable & Improved & \\
\hline
\end{tabular}

Improvement in the symptoms, activity, impact and total score was seen in $8(44 \%), 5(28 \%), 7(39 \%)$ and $6(33 \%)$ of the patients respectively. Stability in the symptoms, activity, impact and total score was seen in $6(33 \%), 7(39 \%), 2(11 \%)$ and $3(17 \%)$ of the patients respectively. Deterioration in the symptoms, activity, impact and total score was seen in $4(22 \%), 6(33 \%), 9(47 \%)$ and $9(47 \%)$ of the patients respectively. COPD: Chronic obstructive pulmonary disease, SCLC , Small cell lung cancer, BAE- Bronchial artery embolization, M -Male, F Female, OPAT- Out Patient Parenteral Antimicrobial Therapy, MRC-Medical Research Council, $\mathrm{X}_{0}$ at start of OPAT, $\mathrm{X}_{3}$ three months into OPAT..

This article is protected by copyright. All rights reserved. 